\title{
Telecoupling: A new frontier for global sustainability
}

\author{
Vanessa Hull $^{1}$ and Jianguo Liu $^{2}$
}

\begin{abstract}
Telecoupling refers to socioeconomic and environmental interactions between distant coupled human and natural systems, and has become more extensive and intensive in the globalized era. The integrated framework of telecoupling examines flows of information, energy, matter, people, organisms, and other things such as financial capital and goods and products around the globe. It pinpoints causes and effects arising from engagement of diverse agents in the global sphere. This first special feature on telecoupling includes 16 articles that explore diverse telecouplings including trade, migration, tourism, information exchange, and transnational product certification schemes. Here we synthesize the articles by describing eight overarching lessons learned. These include the impact of physical, social, and institutional distance on telecouplings, key roles of agents and their inter-relationships, and the important function of telecoupling in enhancing information signals over long distances. Several lessons directly apply to global sustainability challenges, such as the importance of recognizing trade-offs between local and global sustainability and the need for multi-level management and governance solutions. We also suggest five areas of future research to help propel this nascent field forward and further cement its applicability to addressing global sustainability challenges.
\end{abstract}

Key Words: coupled human and natural systems; feedbacks; globalization; telecoupling; spillover

\section{INTRODUCTION}

In today's globalized world, distant places are connected to one another in surprising ways (Liu et al. 2013, Sun et al. 2018). A person can hike in a remote mountain in a far corner of the Himalayas and encounter other people hailing from all over the world whose footprints have lasting impacts long after they have left. Economic instability in one country can cause food prices to soar, affecting trade relationships between multiple other countries and in turn trickling down to alter far away villages and ecosystems (Eakin et al. 2017). As global interconnections such as these increase, their effects become increasingly difficult to understand and predict. But at a time in history marked by interconnected, large-scale global sustainability challenges such as feeding the growing human population, addressing alarming rates of climate change, and tackling diffuse pollution spread (United Nations 2018), a greater understanding of the increasingly visible threads connecting distant places is urgently needed.

Traditional approaches to both research and management alone may be unable to handle such complexity due to the tendency to focus on single places and to remain entrenched within individual disciplinary "silos" (Liu et al. 2013, Liu et al. 2015). The recently proposed framework of telecoupling is a transdisciplinary and multi-level solution to overcome these limitations (Liu et al. 2013). A telecoupling is a process that connects distant systems. Examples include trade, migration, tourism, air circulation, and technology or information transfer over distances. Telecouplings have five major components- systems, agents, flows, causes, and effects (Liu et al. 2013). Distant coupled human and natural systems (systems in which humans and nature interact) are classified according to whether they are engaged in "sending" or "receiving" flows (of information, energy, or matter) from other systems, or being affected by the interactions between sending and receiving systems as a "spillover" system (e.g., as a third party in a trade agreement or a recipient of pollution leakage). The complex (and potentially bidirectional) flows are examined along with the behavior of multiple interacting agents who may operate at multiple levels within and across systems. Causes and effects of the telecoupling are also explicated. These components crosscut multiple disciplines and sectors, encompassing for example technological or social processes, biophysical and climatic drivers and changes, and economic boom and bust cycles.

Publications on telecoupling are scattered in a variety of outlets (e.g., Eakin et al. 2014, Fang et al. 2016, Leisz et al. 2016, Liu et al. 2016, Wang and Liu 2016, Yang et al. 2016, Friis and Nielsen 2017b, Hulina et al. 2017, Silva et al. 2017, Sun et al. 2017, Torres et al. 2017, McCord et al. 2018, Schröter et al. 2018, Yao et al. 2018). However, a special feature on telecoupling is lacking. Thus, we organized the first special feature entitled Telecoupling: A New Frontier for Global Sustainability with the goal of highlighting and synthesizing some of the most recent advances in this exciting field. The feature includes a collection of 16 articles authored by researchers and practitioners with expertise in diverse disciplines from countries all over the world. From seabird watching off the tip of South America, to trekking through banana plantations in Laos, to dairy farming in the midwestern USA, the special feature takes the reader on a rich and telecoupled journey around the world. Collectively, the articles provide a new sense of definition and shape to this nascent field by pinpointing key approaches, questions, and insights into how distant corners of the world are connected to one another in surprising ways. In this editorial, we (1) provide a broad scope of the special feature, (2) draw eight lessons learned from a collective analysis of the featured papers, and (3) propose five new directions for future research to build upon this special feature's foundation.

\section{SCOPE OF THE SPECIAL FEATURE}

Across the special feature, the most common type of telecoupling studied was trade (examined in 11 of the 16 articles). Traded items varied widely from wood pellets (Parish et al. 2018), metals (Xiong et al. 2018), wildlife products (Carrasco et al. 2017), food (Eakin et al. 2017), and fishmeal (Carlson et al. 2018) (Fig. 1). Other telecouplings examined included animal migration (López-

${ }^{1}$ Department of Wildlife Ecology and Conservation, University of Florida, ${ }^{2}$ Center for Systems Integration and Sustainability, Michigan State University 
Fig. 1. Schematic illustrating the major telecouplings (on the circle) and associated examples (bubbles) explored in the special feature.

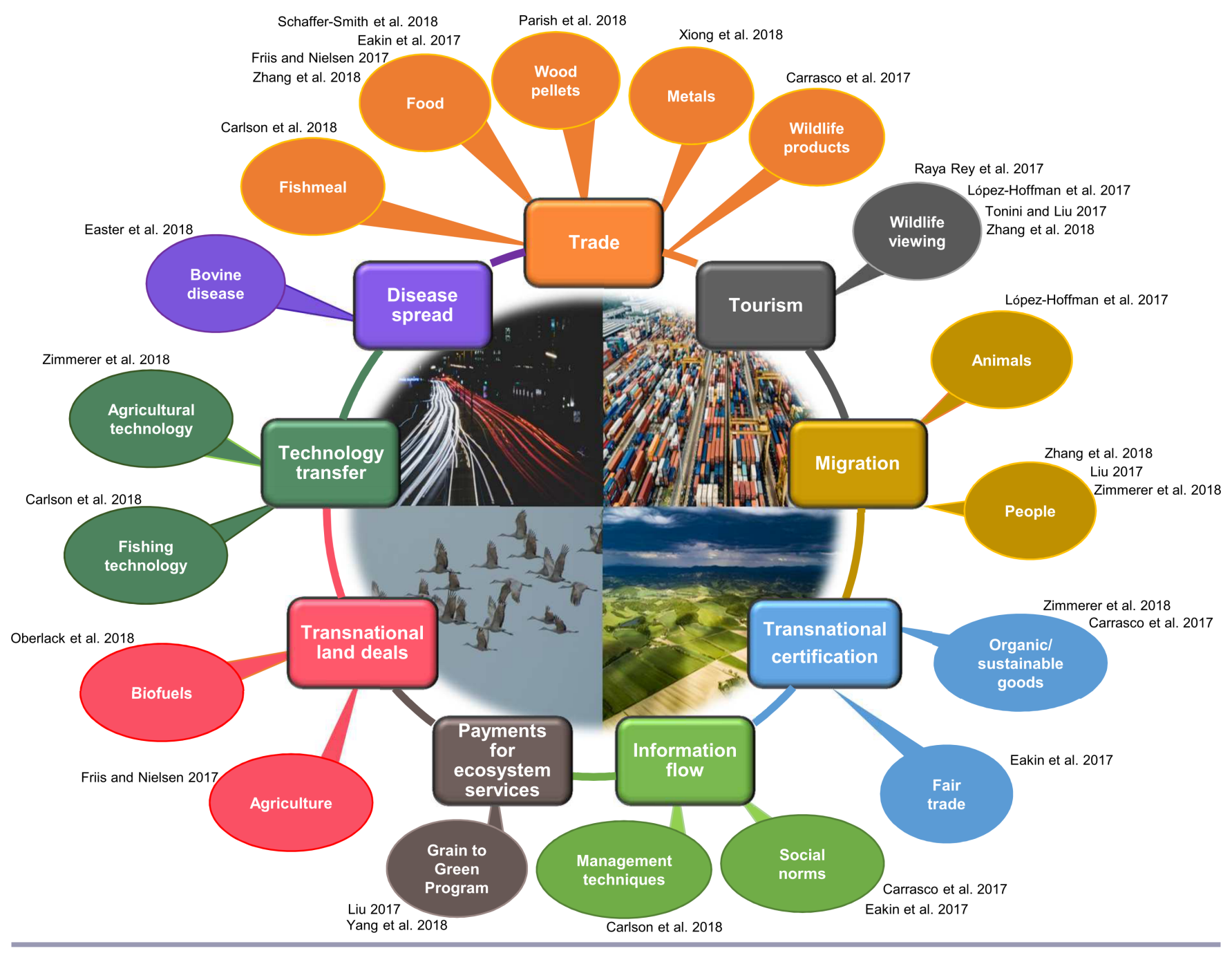

Hoffman et al. 2017), human migration (Carlson et al. 2018, Zhang et al. 2018), tourism (Raya Rey et al. 2017), payments for ecosystem services (Yang et al. 2018), transnational product certification schemes (Carrasco et al. 2017, Eakin et al. 2017), disease spread (Easter et al. 2018), transnational land grabbing (Oberlack et al. 2018), technology transfer (Zimmerer et al. 2018), and information spread (Carrasco et al. 2017, Carlson et al. 2018).

The authors adopted a range of approaches to examine telecoupling. Some studies built or expanded upon conceptual frameworks (Liu 2017, Zimmerer et al. 2018). Others conducted in-depth case studies on the impact of distant processes on single focal systems (Friis and Nielsen 2017a, Oberlack et al. 2018, Yang et al. 2018, Zhang et al. 2018). This approach revealed valuable insights, even if it was not logistically feasible to analyze all possible interactions among multiple distant systems. Other papers adopted a comparative case study analysis across multiple places to ascertain broad patterns and trends (Eakin et al. 2017, Zimmerer et al. 2018). Friis and Nielsen (2017a) conducted ethnographic, qualitative fieldwork to understand the effect of culture and sense of place on the involvement of a local system in a global phenomenon. There were also several examples of quantitative analysis. These included network analysis (SchafferSmith et al. 2018), input-output analysis (Xiong et al. 2018), GIS toolbox development (Tonini and Liu 2017), and a spatial subsidies approach (López-Hoffman et al. 2017). Several studies emphasized the value of telecoupling for complementing (as opposed to overriding) local place-based approaches (Carrasco et al. 2017, Friis and Nielsen 2017a). Integrating telecoupling together with place-based approaches offered the benefits of linking in-depth historical and cultural context with broad systems-level network complexities (Friis and Nielsen 2017a).

Systems examined in the studies varied by geographical region and in scope (Fig. 2). Countries spanned diverse cultural and socioeconomic contexts, including the United States, China, the United Kingdom, Argentina, Bolivia, Laos, South Africa, and Mexico. Some studies examined sending and receiving systems that were local in scale, for instance a single protected area (Yang 
Fig. 2. Map showing spatial extent of representative flows from select telecouplings explored in the special feature.

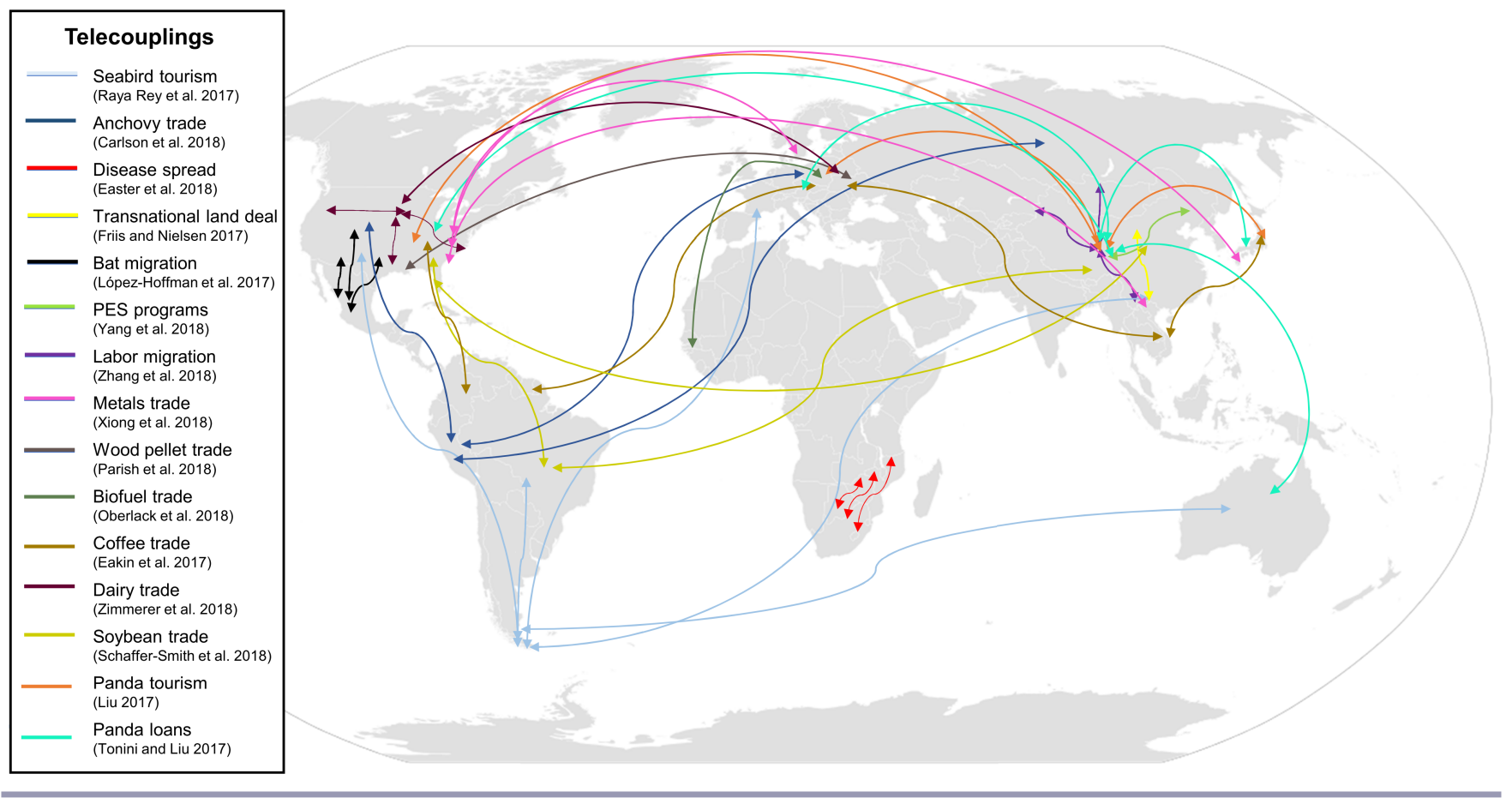

et al. 2018, Zhang et al. 2018) or plantation (Friis and Nielsen 2017a). Other studies treated sending and receiving systems as whole countries, for example via examining national level trade relationships (Xiong et al. 2018). Spillover systems were diffuse, including specific third-party countries involved in trade deals (Carlson et al. 2018, Xiong et al. 2018) or those impacted by the non-target spread of greenhouse gases across boundaries (Parish et al. 2018, Xiong et al. 2018).

Flows examined in the studies encompassed distant transfers of money and goods. Many of the studies noted increases in flows of both in recent years due in part to changes in lifestyles in wealthy developed countries that have increased demand for products, including bananas (Friis and Nielsen 2017a), coffee (Eakin et al. 2017), and niche products like argan oil (Zimmerer et al. 2018). Studies also examined informational exchanges that are often ignored in non-telecoupling research. Examples included knowledge spread across countries about effective marine zoning system design strategies to protect local fishing rights and promote more sustainable industries (Carlson et al. 2018). Similarly, Eakin et al. (2017) addressed how institutional norms involved in the coffee trade spread from consuming countries to producing countries, manifesting in a transfer of business culture.

The special feature also highlighted the complexity of Agents involved in telecouplings. Diverse agents included farmers, fishermen, buyers, trade entities, governments, animals, tourists, NGOs, landowners, and international corporations. Parish et al (2018) proposed classifications of agents to help parse out their relative roles. These included "primary agents", "facilitating agents", and "constraining agents". In the example of wood pellet trade between the southeastern USA and Europe, primary agents included landowners and buyers, facilitating agents included ship and cargo transporters, and constraining agents included environmental NGOs that sought to halt the production of wood pellets from forests.

Causes of telecouplings were also diverse across studies, as exemplified by the complex interactions among many different environmental and socioeconomic causes. For example, ideal climate conditions in Peru due to El Niño / La Niña forces contributed to the growth of the anchovy fish trade from Peru to other countries, but increasing global demand for fish meal to supply growing aquaculture and agricultural feed needs and improvements in fishing technology also played a role (Carlson et al. 2018). Similarly, Chinese agricultural companies were attracted to Laos as a place to grow bananas since warm climates allow bananas to be planted year-round. Yet the influx of Chinese banana plantation companies into Laos was also facilitated by good political relationships between the two countries (whereas China and the Philippines were at odds over the South China Sea) (Friis and Nielsen 2017a).

Effects of telecouplings across the articles were varied and complex. They included positive or negative environmental and socioeconomic effects throughout multiple systems. Example environmental effects include soil and groundwater pollution tied to excess fertilizer and pesticide use on banana plantations in Laos by Chinese firms (Friis and Nielsen 2017a) and pollution involving metal production in developing nations to benefit developed nations (Xiong et al 2018). On the socioeconomic side, Oberlack et al. (2018) discussed loss of "livelihood resilience" among local farmers in Sierra Leonne who were contracted land for biofuel for the European Union (EU). Farmers lost access to resources, social inequalities were reinforced, and tension in the 
region increased. Similarly, Eakin et al. (2017) discussed the effects of the ethanol industry (coupled with a variety of other factors) on the pronounced $70 \%$ spike in tortilla prices in Mexico, which included protests and unrest for urban poor families who relied heavily on this industry.

Effects of telecouplings can also be positive for sustainability, however. Zimmerer et al. (2018) discussed multiple examples involving rural smallholders around the world. Bolivian farmers with income tied to temporary migration supported higher local diversity of agricrops, croplands growing coffee that was certified by international markets in Colombia had higher tree cover than others, and organic milk dairy farms in the US that were regulated by distant national organic standards provided better plant resources for local pollinators and less nitrogen input into local waterways (Zimmerer et al. 2018). Telecouplings can also improve social networks and foster better local-international information exchange, such as in the form of technical assistance programs for coffee farmers in Colombia that are part of an international coffee certification program (Zimmerer et al. 2018). Eakin et al. (2017) discussed a related benefit of having telecouplings encourage the formation of new governance rules or bodies to deal with emerging global issues. An example is the formation of new international certifying bodies to serve the evolving organic coffee trade that expanded after the collapse of the International Coffee Agreement (Eakin et al. 2017).

\section{TELECOUPLING UNLOCKED- 8 LESSONS LEARNED}

\section{Boundaries are fluid and multidimensional}

One recurring message throughout the special feature was that the telecoupling framework helps to overcome a common tendency to box a research project into rigid system boundaries. The telecoupling framework can help resist the temptation to narrowly define a research question according to a dichotomy of "local" versus "global" and instead allow for diffuse interactions at multiple scales (Friis and Nielsen 2017a) or as fluid networks that transcend a traditional nested paradigm (Oberlack et al. 2018). In fact, in telecoupling research, system boundaries do not need to be defined in advance and can evolve as the research unfolds (Eakin et al. 2017, Friis and Nielsen 2017a, Liu 2017). For instance, Friis and Nielsen (2017a) began their research on two banana plantations in Laos and expanded their understanding of the system and its flows to distant places over time after talking to informants.

The telecoupling framework also lets the researcher embrace the idea that distance is relative, such that an interaction occurring over a $1 \mathrm{~km}$ separation could be considered "distant" for some processes (e.g. nutrient cycling and fish harvesting interactions in a lake) but "nearby" for other processes (e.g., long-distance animal migration and tourism interactions) (Liu 2017). Liu (2017) presented a new framework called "metacoupling" that embraces this idea and offers much flexibility. Under this framework, telecouplings between distant coupled human and natural systems can interact with pericouplings (interactions among neighboring systems) and intracouplings (human-nature interactions within a single system). Because the basic structures of the telecoupling and pericoupling frameworks are the same, one can use either the telecoupling framework if the distance is viewed as long or the pericoupling framework if the distance is viewed as short. This metacoupling framework can help differentiate among for example the effects of anchovy trade dynamics in Peru on the direct neighbor of Chile (Carlson et al. 2018) versus longer distance relationships such as European tourists traveling to the Beagle Channel off of the southern tip of South America (Raya Rey et al. 2017).

Telecoupling research also reveals that the impact of system interactions depends not only on physical distances, but also institutional and social distances (Eakin et al. 2017). A system could be physically adjacent to another system but institutionally distant if there are few shared governance arrangements between the systems or socially distant if there are few linkages of social networks, values, and knowledge among the systems (Eakin et al. 2017). This was seen in the example of geographically adjacent countries Chile and Argentina which do not collaborate on shared natural resource conservation issues in the Beagle Channel, even though they are both connected closely to more distant countries on other continents via tourist exchange (Raya Rey et al. 2017). A system that is closely institutionally and socially connected to other distant systems may be better positioned to build on existing connections and to evolve and establish new connections over time as conditions change, as was observed in the coffee market which connects distant countries all over the world (Eakin et al. 2017).

\section{Agents evolve and interact to drive telecouplings}

Agents have powerful roles in the globalized world, as now more than any other time in history can a local actor have a global impact (Eakin et al. 2017). In addition, as the world is becoming increasingly telecoupled, new agents are emerging across distant places that have not been seen before (Eakin et al. 2017). For example, transnational corporations that are not nested within one particular nation (e.g., international agribusiness firms like Cargill) have emerged to address food governance (Eakin et al. 2017). There are also "hybrid institutions" that are created based on collaborations across state, market, and civil society (Eakin et al. 2017, Zimmerer et al. 2018). Telecoupling framework provides a mechanism for understanding the behavior of these diffuse agents as they move and direct flows over distances.

Relationships among agents are also important. For instance, informal interactions among agents were an important driver of the telecoupling of large-scale banana plantation expansion by Chinese companies in neighboring Laos (Friis and Nielsen 2017a). Chinese businesspeople who had over time established their own informal ties within local Laos communities successfully implemented a large-scale land transformation that circumvented formal relationships and government intervention. This later led to sustainability challenges due to individual agents moving faster than top-down regulation could be created to regulate land conversion and pollution (Friis and Nielsen 2017a). As Raya Rey et al. (2017) highlighted, global interconnections set up higher risks for "tragedy of the commons" situations such as these where resource use from outside agents happens so fast that self-interest from outside pressures overrides existing collective shared systems.

Several authors in the special feature stressed the key role of inequalities and inherent power structures among agents (Eakin et al. 2017, Oberlack et al. 2018). Telecoupling can reinforce existing inequalities, such as in the case of investment in biofuels 
for European markets (over local food crops) by farmers in Sierra Leonne (Oberlack et al. 2018). Men in prominent families negotiated the deals with European companies, agreements were written in English with no real efforts to reach out to different voices in the community who may not have known their rights or how to negotiate (Oberlack et al. 2018). Women in particular lost access to key resources. Agents thus need to be appreciated for their heterogeneity and varied positioning in the growth or dampening of future telecouplings.

\section{Telecoupling framework bridges the gap between lost signals}

Another recurring lesson from the special feature was that globalization has caused increasing disconnects between "signals" and "drivers" (Friis and Nielsen 2017a). This is caused by a blockage in the information flow across distances. For example, after a major earthquake in Wolong Nature Reserve, a rural protected area in China, the recovery of the local economy was initially slow because signals about the local needs and disaster effects were not making it back fast enough to the central government to spur large-scale relief efforts (Liu 2017, Zhang et al. 2018). Similarly, biofuel agreements for land in Sierra Leone were crafted in Europe by agents who lacked an understanding of local land tenure practices, leading to agreements that caused conflict because they were too distant and culturally insensitive to fit in the customary land tenure context of Sierra Leone (Oberlack et al. 2018).

In turn, it has become increasingly difficult to trace identity (and in turn responsibility) as global processes become more and more distant from one another (Carrasco et al. 2017, Eakin et al. 2017). For instance, people purchase products on a daily basis from all over the world, but they may not realize where the items (and their derivatives) come from and the nature of their local and global impacts. There is an increasing desire to bridge this gap and recover these lost signals. The food industry, for example, is transitioning from a paradigm of "food from nowhere" to "food from somewhere" (Eakin et al. 2017). The industry (and consumers) want to know where things come from and also who produced it. There is a desire to "reconnect food to place and identity" (Eakin et al. 2017). This is reflected in the global surge of certification schemes and fair trade regulations.

The telecoupling framework can help identify and bridge these gaps. One of the ways that information signals can be enhanced is via taking advantage of digital information flows. Carrasco et al. (2017) discussed the power of the internet and social media for facilitating knowledge spread in ways that can either enhance and hinder sustainability goals (e.g., cracking down on poaching using online tools vs. sale of illegal wildlife parts online). This idea was also discussed by Zimmerer et al. (2018) who referenced cell phone technology and internet as key drivers in spread of technology and information in smallholder agriculture worldwide. Tech savvy owners are adopting new innovations and getting into new markets quicker in the digital age. More recently, there have been companies that seek to use technology to increase traceability of products. An example is the Sustainable Palm Oil Visibility Toolkit (https://www.spott.org) that serves as a public database documenting palm oil company activities (Carrasco et al. 2017).

\section{Multiple telecouplings are linked}

Another important lesson from the special feature was that telecouplings are linked to other telecouplings. For example, trade markets are often linked across products. The collapse of the anchovy population in the 1970 s caused a shortage of fish meal worldwide, which contributed to increased soybean production (as an alternative for animal feeds) in the USA at the expense of wheat production. Wheat prices then soared to almost double the price, leading to wheat shortages in distant developing countries (Carlson et al. 2018). Multi-telecoupling interactions have also taken on new forms in the globalized era. For example, the 2002 Farm Bill in the US gave farmers incentives to grow biofuels, in effect coupling the food and energy markets for the first time (Eakin et al. 2017). This and other similar global policies set the stage for complex competition between food and fuel across farms in the US and other countries worldwide as biofuels gained popularity.

Links among different telecouplings can also include technology or information exchange. For instance, Zimmerer et al. (2018) discussed how dairy farmers in the Midwest US relied on imported technology for storing milk that originated from the UK in order to engage in the organic farming market with distant buyers in other parts of the US. The farmers also engaged in an agricultural cooperative to connect with distant markets using other forms of information technology such as social media.

\section{Policies are feedbacks that make or break a telecoupling}

Another recurring message in this special feature was that policies are needed in many telecouplings, particularly newly emerging ones, to act as negative feedbacks that can prevent sudden and rapid losses in sustainability. For example, global fisheries overharvesting has inspired many governments to enact regulations to control allowable harvest, with some success in tempering fish population declines (Carlson et al. 2018). A contrasting failed policy example was the aforementioned banana plantations owned by Chinese companies newly emerging in Laos where the plantations formed quicker than the government could create policies to control it (Friis and Nielsen 2017a).

Powerful feedbacks can also happen as a pushback after policies fail. A kind of counter-culture arises when new institutions are formed to "put the pieces back together" after a failed policy (Eakin et al. 2017). For instance, after the collapse of the global coffee industry, eco-certification of coffee emerged as a new telecoupling and new institutions and regulations were formed (Eakin et al. 2017). New "counter" feedbacks such as these can also arise at local levels, for example, via the formation of community-based resistance in Sierra Leone in opposition to loss of land tenure rights after the European biofuel telecoupling that stripped them of their rights (Oberlack et al. 2018).

Telecoupling research also reveals the power of diplomacy as a feedback. Improved diplomacy among distant countries (as a byproduct of international policy agreements) is an underappreciated consequence of a telecoupling that can have cascading effects on diverse distant processes. For example, the growth of the anchovy trade between Peru and the Soviet Union not only helped improve economic relationships between the two countries, but also helped promote education and military development (Carlson et al. 2018). Hundreds of Peruvian students were given the opportunity to travel to the Soviet Union 
and allied countries for study and Soviet Union military vessels were given access to Peruvian ports (Carlson et al. 2018).

\section{Sustainability of parts does not equal sustainability of the whole}

Another key lesson learned was that the telecoupling framework identifies disconnects in sustainability gains and losses across space. In other words, making gains toward sustainability in one place may occur at the expense of sustainability losses in other places or even at the expense of overall sustainability at the global scale. For instance, Europe has targeted the southeastern US as a source for wood pellets to meet alternative energy targets, in part because shipping over water is cheaper than shipping from a closer location within Europe (Parish et al. 2018). This improves the efficiency of the market and helps forward the goals of meeting clean energy targets in European countries. However, the longer shipping distance increases GHG emissions, in turn offsetting the broader goal of improving overall global emissions (Parish et al. 2018).

Lower income ("developing") countries often bear the brunt of social and ecological costs from high income countries that benefit from improved access to resources. For instance, Xiong et al. (2018) found that in the global metals trade, developing nations were bearing the burden of the global environmental metals footprint, in part because they had less stringent environmental regulations that made production cheaper, thus reinforcing the telecoupling to the benefit of developed nations but to the detriment of increasingly polluted developing countries. Carrsaco (2017) noted this same trade-off in international wildlife trade patterns. Oberlack (2018) reiterated that increasing interconnectedness among systems introduces new conflicts of interest, making it difficult to determine who should have the "right" to use which resources.

One potential way to directly quantify these trade-offs was demonstrated by López-Hoffman et al. (2017) via the spatial subsidy approach. A spatial subsidy is the "net difference between sent contribution and received benefit" of each system in a telecoupling (López-Hoffman et al. 2017). The authors demonstrated this approach using the example of ecosystem services provided by migratory Mexican free-tailed bats (via pest control of agricultural crops and tourism revenue). Conceptualizing conservation in terms of "subsidies" allowed the researchers to identify "winners" and "losers" and point out hidden costs across the migration pathway. This approach demonstrated how the costs of agricultural production in the southern US were disproportionately burdened onto people of Mexico who were paying money to conserve bat habitat but not receiving proportional benefits. The strength of the cross-national dependency that was demonstrated can be used to potentially inform an international agreement between the two countries in the future on migratory bat conservation (López-Hoffman et al. 2017).

\section{Telecoupling affects resilience}

One overarching question that crosscuts many telecoupling studies is- under which conditions is a local system benefitted or harmed from being increasingly connected to other distant systems? In turn, is a system more or less resilient when it is connected to other systems via telecouplings? The answers are complex and context-dependent. Some systems that have historically been more remote than others may experience instability due to telecouplings, as they may be unable to handle the disruption from boom-bust cycles in international markets or the impacts of economic recessions in distant countries (Raya Rey et al. 2017). In the case of increased international tourism in the remote Beagle Channel, local economies have benefited from the telecoupling, but the system is in other ways ill-equipped to handle the influx of the people from all over the world. For example, the system lacks an adequate sewer system to handle basic waste disposal (Raya Rey et al. 2017).

On the other hand, telecoupling can promote resilience in a system if the social distance across the systems is small, despite the physical distances perhaps being large (Eakin et al. 2017). The adaptability of the coffee market in Colombia is an example of this, as the system was able to quickly bounce back when soaring coffee prices caused a global humanitarian crisis. The government initiated changes in institutions by enacting new certification schemes. Their ability to adapt was in part assisted by strong existing social relationships with distal agents from all over the world that were also engaged in coffee certification. A caveat to this is that asymmetry among agents can impede this process if some agents have less incentive to adapt to shocks than others (Eakin et al. 2017).

Resilience may also be related to how broad or narrow the telecoupling is. Food trade involves common crops that flow all over the world such as corn, wheat, or coffee in contrast to narrow market niche commodities like argan oil that may only be grown in specific areas and are produced by some of the poorest people for the rich elites of the world (Zimmerer et al. 2018). Flows limited to narrower markets may be more vulnerable to shocks, as shown in the contrast between the collapse of the Mexican tortilla market in recent years, a product that has a more culturally and geographically localized presence, compared to the more ubiquitous coffee market (Eakin et al. 2017).

Zhang et al. (2018) presented an interesting case of what happens when a system becomes suddenly cut off from the rest of the world due to a natural disaster. In Wolong Nature Reserve for giant pandas in rural China, an earthquake completely removed nearly all telecouplings that this rural protected area had with the outside world due to massive destruction of the roads and collapse of the local agricultural and tourist markets. In this case, the prior heavy reliance of the system on telecouplings with the outside world made it more vulnerable when a disaster struck, but new telecouplings (in the form of government aid) emerged and helped pull the system out of a state of collapse. The new system has been in the process of taking shape and has different structure than it did prior to the disturbance. This example highlights how telecoupling can act as both a source of vulnerability and a source of increased resilience.

\section{Multi-level sustainability solutions are needed}

Telecoupling framework also helps parse out where management efforts originate (e.g., local, adjacent, or distant) and helps identify which is the most effective for a given problem (Liu 2017). Several authors pointed to an importance of a strong local management or governance. For example, local cooperatives are key in smallholder agriculture initiatives to make sure benefits stay local instead of being displaced elsewhere (Zimmerer et al. 2018). Local certification programs have helped set sustainable 
guidelines for tourism of seabirds in the Beagle Channel (Raya Rey et al. 2017). In contrast, in the example of argan oil trade, the failure of this niche market to achieve local sustainability goals was in large part due to too much central government hoarding benefits and not enough local control over the market (Zimmerer et al. 2018). Nonetheless, at national levels, land tenure laws, organic food standards, and fair trade certification standards can also be powerful mechanisms to promote local sustainability for some telecouplings (Carrasco et al. 2017, Eakin et al. 2017, Zimmerer et al. 2018). National or international level regulations on for example wildlife trade or food pricing are also crucial in ensuring sustainability when flows of products go beyond local jurisdictions (Carrasco et al. 2017).

Considering the variation in costs and benefits in each of these approaches, the most effective management or governance solution may often be a multi-level one. In the example of transnational land investments, local institutions may be too overwhelmed to handle the pressures from the complex global land grabbing market, but on the other hand national institutions may be too distant to be able to be effective at the local level (Oberlack et al. 2018). To overcome these limitations, Oberlack et al. (2018) advocated for a kind of coordinated governance across different institutions and areas, similar to the polycentric governance framework. A related powerful way to connect across institutions and scales is to foster what Zimmerer et al. (2018) termed Public and Private Mediating Institutions. These institutions act to foster flows of information between levels and across local and global spheres to help strengthen connections and prevent lost signals.

\section{PATHWAYS FORWARD}

The telecoupling special feature breaks new ground in exploring this interdisciplinary framework. But many unanswered questions remain and new opportunities for expansion of this field are on the horizon. We encourage more researchers and practitioners to join in and contribute new ideas and approaches. We outline five areas for potential future work below, but stress that this is not an exhaustive list of possibilities.

\section{Understanding information spread in the technology age} One interesting avenue of inquiry is to better understand the role of social media and communication technology in shaping information spread and related telecoupling processes. Several authors mentioned the importance of these phenomena (Carrasco et al. 2017, Zimmerer et al. 2018), but little is known about mechanisms for how they operate. For instance, why do some sustainability causes go viral on social media and others don't (Carrasco et al. 2017)? How does the information spread and how can we harness its impact on social norms in positive ways for sustainability (Carrasco et al. 2017)?

\section{Improving traceability of global products}

Some papers in the special issue also touched on the increasing need to be able to trace flows over long distances to pinpoint where things come from and the associated impacts they have along their travel pathway (e.g., via eco-certification) (Carrasco et al. 2017). Further work needs to evaluate whether tracing mechanisms and technologies (e.g., blockchain) work for improving sustainability (e.g., via linking purchasing data with land use change data) (Carrasco et al. 2017). What other unique ways can we use traceable data to answer global sustainability questions?

\section{Pinpointing nebulous spillover effects}

There are relatively little data or analyses on spillover effects (Liu et al. 2018, Parish et al. 2018). A few papers in the special issue addressed spillovers. For example, Zimmerer et al. (2018) talked about local spillovers among neighboring farmers in Bolivia who engaged in resource coordination among neighbors to increase efficiency, resulting in spatial clustering. Xiong et al. (2018) discussed global spillovers in how some countries that import more intermediate parts to build metal products (for later export) have higher spillover effects than other countries due to their interactions in the multi-step production process. But more needs to be done to address broad questions such as: which factors determine how far a spillover effect spreads? Which factors make a system more likely to cause a spillover? How can agents better predict potential negative spillovers before they happen?

\section{Quantifying distant feedbacks}

Research on feedbacks is an ongoing need in the telecoupling literature. Feedbacks are complex and often require multiple time points of data. But they play powerful roles in either promoting or dampening telecouplings, as was demonstrated in the policy examples we highlighted here. Surprising feedbacks that are otherwise undetected using other approaches (e.g., the diplomacy example with the Peruvian anchovy trade impacting education exchange with other countries) are interesting and untapped. What makes a telecoupling feedback tighter or looser? How can we assign causality to feedbacks that seem diffuse and difficult to link?

\section{Delving further into multi-leveled telecoupling}

Many of the authors in this special feature explored telecouplings as they formed and changed shape across different levels of organization. These phenomena involved complex interactions and feedbacks between local, regional, and global levels. But the field is just beginning to understand these processes. How do local and neighboring interactions shape more distant interactions and vice versa? How do local concepts translate or percolate up to higher levels? For instance, Raya Rey et al. (2017) posed the question: how does the sociological "sense of place" or attachment to a local system translate in an increasingly globalized world? Is attachment to place diluted as people migrate? Or is it transformed or multiplied across space? Liu's (2017) new multi-level conceptual framework called metacoupling may be a useful starting point for further investigation into these issues.

\section{CONCLUSION}

It is a dynamic time for telecoupling research with many opportunities for growth on the horizon that may help address complex global sustainability challenges. The special feature provides a solid foundation upon which to understand how distal agents interact, how sustainability in one place is affected by other places, and how information flows can either be lost or maintained over physical, social, and institutional distances. The special feature also demonstrates how telecoupling can elucidate how to structure multi-level management approaches and how to avoid unintended trade-offs that disproportionately burden some agents or systems over others. Going forward, further development of telecoupling toolboxes is needed to address the questions proposed in the future directions section. Creativity is needed to adapt existing approaches and expand them to other disciplines and come up with new indices and analytical approaches to address multi-level and networked processes. 
Perhaps most importantly, what will be crucial in further positioning telecoupling to better address sustainability needs in the globalized era is a continued commitment to fostering interdisciplinarity and global collaboration among telecoupled places.

Responses to this article can be read online at: http://www.ecologyandsociety.org/issues/responses. php/10494

\begin{abstract}
Acknowledgments:
We are grateful to the authors of this special feature for their time and efforts. We particularly thank the numerous reviewers who spent lots of time and patience in reviewing and improving the papers many papers were reviewed three or four rounds. Help and guidance from the editor-in-chief Carl Folke and managing editor Jennifer Mullie are greatly appreciated. Most of the papers included in this special feature emerged from a workshop and symposium on telecoupling held at the 2016 annual meeting of the US Regional Association of the International Association for Landscape Ecology in Asheville, NC as part of the NASA-MSU Professional Enhancement Program. Funding was provided by the U.S. National Science Foundation, NASA, Michigan State University, and Michigan AgBioResearch.
\end{abstract}

\section{LITERATURE CITED}

Carlson, A. K., W. W. Taylor, J. Liu, and I. Orlic. 2018. Peruvian anchoveta as a telecoupled fisheries system. Ecology and Society 23(1):35. http://dx.doi.org/10.5751/ES-09923-230135

Carrasco, L. R., J. Chan, F. L. McGrath, and L. T. P. Nghiem. 2017. Biodiversity conservation in a telecoupled world. Ecology and Society 22(3):24. http://dx.doi.org/10.5751/ES-09448-220324

Eakin, H., R. Defries, S. Kerr, E. F. Lambin, J. Liu, P. J. Marcotullio, P. Messerli, A. Reenberg, X. Rueda, and S. R. Swaffield 2014. Significance of telecoupling for exploration of land-use change. Rethinking global land use in an urban era. MIT Press. http://dx.doi.org/10.7551/mitpress/9780262026901.003.0008

Eakin, H., X. Rueda, and A. Mahanti. 2017. Transforming governance in telecoupled food systems. Ecology and Society 22 (4):32. http://dx.doi.org/10.5751/ES-09831-220432

Easter, T. S., A. K. Killion, and N. H. Carter. 2018. Climate change, cattle, and the challenge of sustainability in a telecoupled system in Africa. Ecology and Society 23(1):10. http://dx.doi. org/10.5751/ES-09872-230110

Fang, B., Y. Tan, C. Li, Y. Cao, J. Liu, P.-J. Schweizer, H. Shi, B. Zhou, H. Chen, and Z. Hu. 2016. Energy sustainability under the framework of telecoupling. Energy 106253-259. http://dx.doi. org/10.1016/j.energy.2016.03.055

Friis, C., and J. Ø. Nielsen. 2017. Land-use change in a telecoupled world: the relevance and applicability of the telecoupling framework in the case of banana plantation expansion in Laos. Ecology and Society 22(4):30. http://dx.doi.org/10.5751/ ES-09480-220430
Friis, C., and J. Ø. Nielsen. 2017b. On the system. Boundary choices, implications, and solutions in telecoupling land use change research. Sustainability 9(6):974.

Hulina, J., C. Bocetti, H. Campa Iii, V. Hull, W. Yang, and J. Liu. 2017. Telecoupling framework for research on migratory species in the Anthropocene. Elementa: Science of the Anthropocene 5. http://dx.doi.org/10.1525/elementa.184

Leisz, S. J., E. Rounds, N. Thi Bich Yen, T. Nguyen Bang, S. Douangphachanh, and B. Ninchaleune. 2016. Telecouplings in the east-west economic corridor within borders and across. Remote Sensing 8(12):1012. http://dx.doi.org/10.3390/rs8121012

Liu, J. 2017. Integration across a metacoupled world. Ecology and Society 22(4):29. http://dx.doi.org/10.5751/ES-09830-220429

Liu, J., Y. Dou, M. Batistella, E. Challies, T. Connor, C. Friis, J. D. Millington, E. Parish, C. L. Romulo, and R. F. B. Silva. 2018. Spillover systems in a telecoupled Anthropocene: typology, methods, and governance for global sustainability. Current Opinion in Environmental Sustainability 3358-69. http://dx.doi. org/10.1016/j.cosust.2018.04.009

Liu, J., V. Hull, M. Batistella, R. DeFries, T. Dietz, F. Fu, T. W. Hertel, R. C. Izaurralde, E. F. Lambin, S. Li, L. A. Martinelli, W. J. McConnell, E. F. Moran, R. Naylor, Z. Ouyang, K. R. Polenske, A. Reenberg, G. de Miranda Rocha, C. S. Simmons, P. H. Verburg, P. M. Vitousek, F. Zhang, and C. Zhu. 2013. Framing sustainability in a telecoupled world. Ecology and Society 18 (2):26. http://dx.doi.org/10.5751/ES-05873-180226

Liu, J., V. Hull, J. Luo, W. Yang, W. Liu, A. Viña, C. Vogt, Z. Xu, H. Yang, J. Zhang, L. An, X. Chen, S. Li, Z. Ouyang, W. Xu and H. Zhang. 2015. Multiple telecouplings and their complex interrelationships. Ecology and Society 20(3):44. http://dx.doi. org/10.5751/ES-07868-200344

Liu, J., W. Yang, and S. Li. 2016. Framing ecosystem services in the telecoupled Anthropocene. Frontiers in Ecology and the Environment 14(1):27-36. http://dx.doi.org/10.1002/16-0188.1

López-Hoffman, L., J. Diffendorfer, R. Wiederholt, K. J. Bagstad, W. E. Thogmartin, G. McCracken, R. L. Medellin, A. Russell, and D. Semmens. 2017. Operationalizing the telecoupling framework for migratory species using the spatial subsidies approach to examine ecosystem services provided by Mexican free-tailed bats. Ecology and Society 22(4):23. http://dx.doi. org/10.5751/ES-09589-220423

McCord, P., F. Tonini, and J. Liu. 2018. The Telecoupling GeoApp: A Web-GIS application to systematically analyze telecouplings and sustainable development. Applied Geography 9616-28. http://dx.doi.org/10.1016/j.apgeog.2018.05.001

Oberlack, C., S. Boillat, S. Brönnimann, J.-D. Gerber, A. Heinimann, C. Ifejika Speranza, P. Messerli, S. Rist, and U. Wiesmann. 2018. Polycentric governance in telecoupled resource systems. Ecology and Society 23(1):16. http://dx.doi.org/10.5751/ ES-09902-230116

Parish, E. S., A. J. Herzberger, C. C. Phifer, and V. H. Dale 2018. Transatlantic wood pellet trade demonstrates telecoupled benefits. Ecology and Society 23(1):28. http://dx.doi.org/10.5751/ ES-09878-230128 
Raya Rey, A. N., J. C. Pizarro, C. B. Anderson, and F. Huettmann. 2017. Even at the uttermost ends of the Earth: how seabirds telecouple the Beagle Channel with regional and global processes that affect environmental conservation and social-ecological sustainability. Ecology and Society 22(4):31. http://dx.doi. org/10.5751/ES-09771-220431

Schaffer-Smith, D., S. Tomscha, K. Jarvis, D. Maguire, M. Treglia, and J. Liu. 2018. Network analysis as a tool for quantifying the dynamics of metacoupled systems: an example using global soybean trade. Ecology and Society 23(3):ZZ. http://dx.doi. org/10.5751/ES-10460-2303ZZ

Schröter, M., T. Koellner, R. Alkemade, S. Arnhold, K. J. Bagstad, K.-H. Erb, K. Frank, T. Kastner, M. Kissinger, and J. Liu. 2018. Interregional flows of ecosystem services: Concepts, typology and four cases. Ecosystem Services 31229-288. http://dx.doi. org/10.1016/j.ecoser.2018.02.003

Silva, R. F. B. D., M. Batistella, Y. Dou, E. Moran, S. M. Torres, and J. Liu. 2017. The Sino-Brazilian telecoupled soybean system and cascading effects for the exporting country. Land 6(3):53. http://dx.doi.org/10.3390/land6030053

Sun, J., H. Mooney, W. Wu, H. Tang, Y. Tong, Z. Xu, B. Huang, Y. Cheng, X. Yang, D. Wei, F. Zhang, and J. Liu. 2018. Importing food damages domestic environment: Evidence from global soybean trade. Proceedings of the National Academy of Sciences 115(21):5415-5419. http://dx.doi.org/10.1073/pnas.1718153115

Sun, J., Y.-X. Tong, and J. Liu. 2017. Telecoupled land-use changes in distant countries. Journal of Integrative Agriculture 16 (2):368-376.

Tonini, F., and J. Liu. 2017. Telecoupling Toolbox: spatially explicit tools for studying telecoupled human and natural systems. Ecology and Society 22(4):11. http://dx.doi.org/10.5751/ ES-09696-220411

Torres, A., J. Brandt, K. Lear, and J. Liu. 2017. A looming tragedy of the sand commons. Science 357(6355):970-971. http://dx.doi. org/10.1126/science.aao0503

United Nations. 2018. UN Sustainable Development Goals. https://sustainabledevelopment.un.org/sdgs.

Wang, F., and J. Liu. 2016. Conservation planning beyond giant pandas: the need for an innovative telecoupling framework. Science China Life Sciences 60(5):551-554. http://dx.doi. org/10.1007/s11427-016-0349-0

Xiong, H., J. D. Millington, and W. Xu. 2018. Trade in the telecoupling framework: evidence from the metals industry. Ecology and Society 23(1):11. http://dx.doi.org/10.5751/ ES-09864-230111

Yang, D., J. Cai, V. Hull, K. Wang, Y. P. Tsang, and J. Liu. 2016. New road for telecoupling global prosperity and ecological sustainability. Ecosystem Health and Sustainability 2(10):e01242. http://dx.doi.org/10.1002/ehs2.1242

Yang, H., F. Lupi, J. Zhang, X. Chen, and J. Liu. 2018. Feedback of telecoupling: the case of a payments for ecosystem services program. Ecology and Society 23(2):45. http://dx.doi.org/10.5751/ ES-10140-230245
Yao, G., T. W. Hertel, and F. Taheripour. 2018. Economic drivers of telecoupling and terrestrial carbon fluxes in the global soybean complex. Global Environmental Change 50190-200. http://dx.doi. org/10.1016/j.gloenvcha.2018.04.005

Zhang, J., T. Connor, H. Yang, Z. Ouyang, S. Li, and J. Liu. 2018. Complex effects of natural disasters on protected areas through altering telecouplings. Ecology and Society 23(3):17. http://dx.doi. org/10.5751/ES-10238-230317

Zimmerer, K. S., E. F. B. Lambin, and S. J. Vanek. 2018. Smallholder telecoupling and potential sustainability. Ecology and Society 23(1):30. http://dx.doi.org/10.5751/ES-09935-230130 